\title{
EFFECTS OF POLYAMINES ON ETHYLMORPHINE N-DEMETHYLATION IN RAT LIVER MICROSOMES
}

\author{
Mitsukazu KITADA, Naoko YAMAGUCHI, Kazuei IGARASHI, \\ Seiyu HIROSE and Haruo KITAGAWA \\ Faculty of Pharmaceutical Sciences, Chiba University, \\ Yayoi-cho, Chiba 280, Japan
}

Accepted March 3, 1980

\begin{abstract}
The time course linearity of ethylmorphine N-demethylation was improved by the addition of polyamines to the reaction mixture. The most remarkable effect on the time course linearity of ethylmorphine $\mathrm{N}$-demethylation was observed when spermine was used. The apparent stimulatory effect of spermine was decreased remarkably by the simultaneous addition of EDTA to inhibit lipid peroxidation. Similar results were observed when an additional lipid peroxidation inhibitor such as $\mathrm{Co}^{2+}, \mathrm{Mn}^{2+}$ or 2,2'-bipyridine was used in place of EDTA. Hydrogen peroxidedependent ethylmorphine $\mathrm{N}$-demethylation activity in rat liver microsomes was not influenced by the addition of spermine. In addition, neither lipid peroxides formation nor the stimulatory effects of polyamines on ethylmorphine $\mathrm{N}$-demethylation was observed in the reconstituted monooxygenase system. These results suggest that the inhibitory effects of polyamines on lipid peroxidation might be responsible for the stimulatory effects on drug oxidations.
\end{abstract}

It is well known that the liver microsomal drug hydroxylation enzyme system metabolizes a variety of drugs, steroids, fatty acids, carcinogens and that other foreign compounds require phospholipid for substrate binding to cytochrome $\mathrm{P}-450$ and electron transport from NADPH to cytochrome P-450 via NADPH-cytochrome $c$ (P-450) reductase $(1,2)$. Recently, Chapman has demonstrated that polyamines significantly stimulated ethylmorphine $\mathrm{N}$ demethylation in both male and female rat liver microsomes (3).

Polyamines have been shown to interact with nucleic acid and phospholipid (4). We have recently demonstrated that both NADPH- and ascorbic acid-dependent microsomal lipid peroxidation which is known to produce oxidative degradation of phospholipid was inhibited by spermine (5). Since the apparent activities of drug hydroxylation in rat liver microsomes are apparently stimulated by lipid peroxidation inhibitors such as EDTA, $\mathrm{Co}^{2+}$ and 1,10-phenanthroline (6), we investigated the relationship between inhibitory effects of polyamines on lipid peroxidation and stimulatory effects of polyamines on drug hydroxylation.

\section{MATERIALS AND METHODS}

Male Wistar rats weighing 120 to $150 \mathrm{~g}$ were maintained on commercial rat chow, CE-2 Nippon Clea Co., Japan and were deprived of food for 18 to $20 \mathrm{hr}$ prior to sacrifice, but were allowed tap water ad libitum. Microsomes were prepared as described previously (7). Microsomal lipids were extracted from intact rat liver microsomes by the method of 
Folch et al. (8).

Cytochrome P-450 was partially purified by the method of Imai and Sato (9) from microsomes of phenobarbital-treated rats given $0.1 \%$ sodium phenobarbital in drinking water for 3 days. Cytochrome P-450 was measured by the method of Omura and Sato (10) using an Aminco DW-2 recording spectrophotometer and the content was calculated from absorbance difference between $450 \mathrm{~nm}$ and $490 \mathrm{~nm}$ using the extinction coefficient of 91 $\mathrm{mM}^{-1} \mathrm{~cm}^{-1}$. The specific content of the cytochrome P-450 preparation was $12.1 \mathrm{nmole}$ per mg of protein.

NADPH-cytochrome $c$ (P-450) reductase was purified from phenobarbital-treated rat liver microsomes by a minor modification of the method of Yasukochi and Masters (11). NADPH-cytochrome $c(\mathrm{P}-450)$ reductase activity was measured by the method of Phillips and Langdon (12) using cytochrome $c$ as an electron acceptor. Specific activity of the purified reductase was 58.8 units per $\mathrm{mg}$ of protein.

The typical reaction mixture for microsomal drug hydroxylation and lipid peroxidation contained $100 \mathrm{mM} \mathrm{Na}, \mathrm{K}$-phosphate (pH 7.4), 0.33 mM NADP, 8 mM glucose 6-phosphate, 0.1 unit glucose 6-phosphate dehydrogenase, $10 \mathrm{mM} \mathrm{MgCl}$, microsomes and a substrate in a final volume of $1 \mathrm{ml}$. When necessary, $0.1 \mathrm{mM}$ EDTA and/or $5 \mathrm{mM}$ of polyamines were added to the reaction mixture. The reaction mixture for microsomal $\mathrm{H}_{2} \mathrm{O}_{2}$-dependent drug oxidation consisted of $100 \mathrm{mM} \mathrm{Na}$, K-phosphate ( $\mathrm{pH}$ 7.4), $0.1 \mathrm{mM}$ EDTA, microsomes and substrate in a final volume of $1 \mathrm{ml}$. After preincubation at $37^{\circ}$ for $1 \mathrm{~min}, \mathrm{H}_{2} \mathrm{O}_{2}$ (final concentration $50 \mathrm{mM}$ ) was added to start the reaction. The reconstituted system of ethylmorphine N-demethylation consisted of $100 \mathrm{mM} \mathrm{Na}, \mathrm{K}$-phosphate ( $\mathrm{pH} 7.4), 0.2$ nmole of cytochrome P-450, 0.5 unit of NADPH-cytochrome $c(\mathrm{P}-450)$ reductase, $5 \mathrm{mM}$ of substrate, NADPH-generating system described above and $0.1 \mathrm{mg}$ of extracted lipid or $30 \mu \mathrm{g}$ of dilauroyl-L-3-phosphatidylcholine in a final volume of $1 \mathrm{ml}$.

Lipid peroxides formed were determined by the thiobarbituric acid (TBA) method, as previously described (13). The formation of lipid peroxides was represented by calculating optical density at $532 \mathrm{~nm}$ per $\mathrm{mg}$ of microsomal protein per $\mathrm{ml}$ of incubation mixture. The formation of formaldehyde was measured by the method of Nash (14), and the formation of $p$-aminophenol from aniline was measured according to the method of Imai et al. (15). Protein was determined according to the method of Lowry et al. (16) using bovine serum albumin as a standard.

NADPH, NADP, glucose 6-phosphate, glucose 6-phosphate dehydrogenase and cytochrome $c$ (horse heart) were purchased from Boehringer Mannheim Co., and dilauroylL-3-phosphatidylcholine was from Serdary Research Laboratories, Canada. 2',5'-ADP Sepharose 4B and DEAE-Sephadex (A-50) were purchased from Pharmacia Fine Chemicals Co., and hydroxylapatite was from Bio-Rad. Thiobarbituric acid was purchased from Daiichi Pure Chemicals Co., Japan. Emulgen 913, a non-ionic detergent, was kindly provided by Kao-Atlas Co. Commercial aniline was redistilled under vacuum and the distillate was stored at $-10^{\circ}$ under an atmosphere of nitrogen. Other chemicals were of the highest purity commercially available. 


\section{RESULTS}

The effects of polyamines on the time course linearity of ethylmorphine N-demethylation were investigated (Fig. 1). The linearity of ethylmorphine $\mathrm{N}$-demethylation activity in the absence of polyamines was diminished within five minutes, but was partially improved by the addition of polyamines. However, the partial restoration of the linearity was dependent upon the species of polyamines used, and spermine produced the most remarkable improvement followed by spermidine and putrescine.

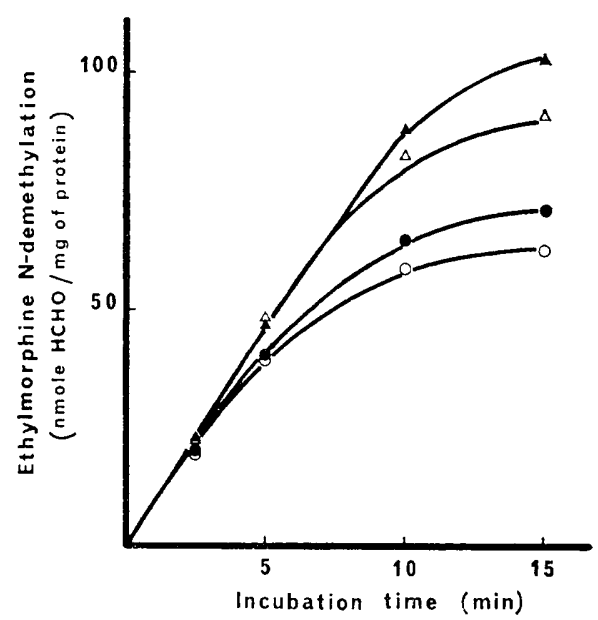

FIG. 1. Effects of polyamines on the time course linearity of ethylmorphine N-demethylation in rat liver microsomes. The concentrations of putrescine (O), spermidine $(\triangle)$ and spermine $(\boldsymbol{\Delta})$ used were $5 \mathrm{mM}$. See MATERIALS AND METHODS for details.

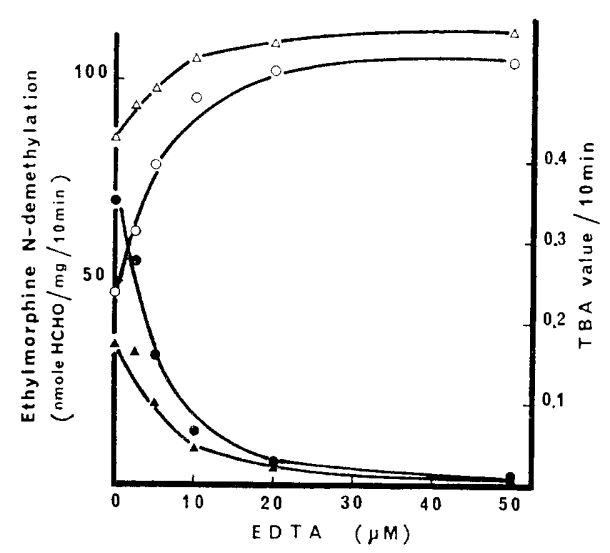

FIG. 2. Effects of EDTA on the stimulatory effect of spermine on ethylmorphine $\mathrm{N}$-demethylation in rat liver microsomes. $\mathrm{N}$-demethylation activity of ethylmorphine and lipid peroxidation were measured in the presence of various concentrations of EDTA, as specified in the figure Ethylmorphine N-demethylation: with spermine $(\triangle)$, without $(\bigcirc)$; lipid peroxidation: with spermine $(\boldsymbol{A})$, without spermine ( The concentration of spermine employed was $5 \mathrm{mM}$. 
The effects of spermine on ethylmorphine N-demethylation in the presence of various concentrations of EDTA were then investigated (Fig. 2). Ethylmorphine N-demethylation activity was increased progressively with increase in the concentration of EDTA whereas lipid peroxidation decreased with increase in the concentration of EDTA. Moreover, spermine exerted additional effects of both ethylmorphine $\mathrm{N}$-demethylation and lipid peroxidation when low concentrations of EDTA were used, but not when high concentrations were used. Effects of spermine on aminopyrine $\mathrm{N}$-demethylation activity and aniline hydroxylation activity in the presence or absence of EDTA are shown in Table 1. Spermine increased in aminopyrine $\mathrm{N}$-demethylation activity by about $30 \%$ in the absence of EDTA but not in the presence of EDTA. On the contrary, as would be expected from previous studies $(17,18)$ in which aniline itself was found to inhibit lipid peroxidation and aniline hydroxylation activity was relatively stable against lipid peroxidation, aniline hydroxylation activity was stimulated by only about $8 \%$ in the presence of EDTA and/or spermine.

As shown in Table 2, spermine produced a significant increase in the activities of ethylmorphine $\mathrm{N}$-demethylation in the absence of $\mathrm{Co}^{2+}, \mathrm{Mn}^{2+}$ or 2,2'-bipyridine whereas simultaneous additions of spermine with $\mathrm{Co}^{2+}, \mathrm{Mn}^{2+}$ or 2,2'-bipyridine, a lipid peroxidation inhibitor, also produced a remarkable decrease in the stimulatory effect of spermine on ethyl-

TABLE 1. Effects of spermine on N-demethylation of aminopyrine and hydroxylation of aniline in the presence or absence of EDTA

\begin{tabular}{lcc}
\hline \multicolumn{1}{c}{ Addition } & $\begin{array}{c}\text { Aminopyrine N-demethylation } \\
(\mathrm{nmole} \mathrm{HCHO} / \mathrm{mg} / 10 \mathrm{~min})\end{array}$ & $\begin{array}{c}\text { Aniline hydroxylation } \\
\text { (nmole } p \text {-aminophenol/mg/10 min) }\end{array}$ \\
None & $35.31 \pm 0.95$ & $10.25 \pm 0.34$ \\
Spermine & $45.56 \pm 0.00$ & $10.98 \pm 0.52$ \\
EDTA & $68.25 \pm 0.95$ & $11.52 \pm 0.16$ \\
Spermine-EDTA & $62.33 ! 0.00$ & $12.52 \pm 0.16$ \\
\hline
\end{tabular}

$\mathrm{N}$-demethylation activity of aminopyrine and hydroxylation activity of aniline were measured as described in MATERIALS AND METHODS. The concentrations of spermine and EDTA employed were $5 \mathrm{mM}$ and $0.1 \mathrm{mM}$, respectively. Each value represents the mean S.D. of duplicate determinations.

TABLE 2. Effects of spermine on ethylmorphine $\mathrm{N}$-demethylation in the presence of $\mathrm{Co}^{2+}, \mathrm{Mn}^{2+}$ OR 2,2'-bipyridine

\begin{tabular}{lcccc}
\hline Addition & $\begin{array}{c}\text { Ethylmorphine } \mathrm{N}-\mathrm{demethylation} \\
\text { (nmole } \mathrm{HCHO} / \mathrm{mg} / 10 \mathrm{~min})\end{array}$ & $\begin{array}{c}\text { Lipid peroxidation } \\
\text { (TBA value/10 min) }\end{array}$ \\
& - spermine & + spermine & - spermine & spermine \\
None & $59.49 \pm 4.58$ & $102.14 \div 8.80^{*}$ & $0.278 \pm 0.031$ & $0.138 \pm 0.056$ \\
$\mathrm{Mn}^{2+}$ & $88.44 \pm 12.73$ & $98.32 \pm 15.11$ & $0.010 \pm 0.002$ & $0.006 \pm 0.001$ \\
$\mathrm{Co}^{2+}$ & $114.74 \pm 12.20$ & $132.92 \pm 14.47$ & $0.005 \pm 0.002$ & $0.005 \pm 0.001$ \\
$2,2^{\prime}$-Bipyridine & $92.39 \pm 12.89$ & $114.46 \pm 12.71$ & $0.007 \pm 0.001$ & $0.006 \pm 0.002$ \\
\hline
\end{tabular}

The concentrations of $\mathrm{Co}^{2+}\left(\right.$ as $\mathrm{CoCl}_{2}$ ), $\mathrm{Mn}^{2+}$ (as $\mathrm{MnCl}_{2}$ ), 2,2'-bipyridine and spermine added to the incubation mixture were $0.5,0.1$ and $5 \mathrm{mM}$, respectively. Each value represents the mean - S.D. of four determinations. *Significantly different $(p<0.01)$ from values obtained in the absence of spermine. 
morphine $\mathrm{N}$-demethylation activity.

It has recently been demonstrated that cytochrome P-450 can accept oxygen from a variety of compounds such as cumene hydroperoxide, hydrogen peroxide, sodium periodate and iodosobenzene and catalyzes hydroxylations of a variety compounds including benzphetamine, $\mathrm{N}$-dimethylaniline, aniline, benzpyrene and some steroids substrates, in the absence of a reducing equivalent (19-22). Therefore, the effects of spermine on $\mathrm{H}_{2} \mathrm{O}_{2}$ dependent ethylmorphine $\mathrm{N}$-demethylation were investigated. As shown in Fig. 3, the addition of spermine did not produce any effect on $\mathrm{H}_{2} \mathrm{O}_{2}$-dependent ethylmorphine $\mathrm{N}$ demethylation. Since polyamines have been shown to interact with phospholipid, the

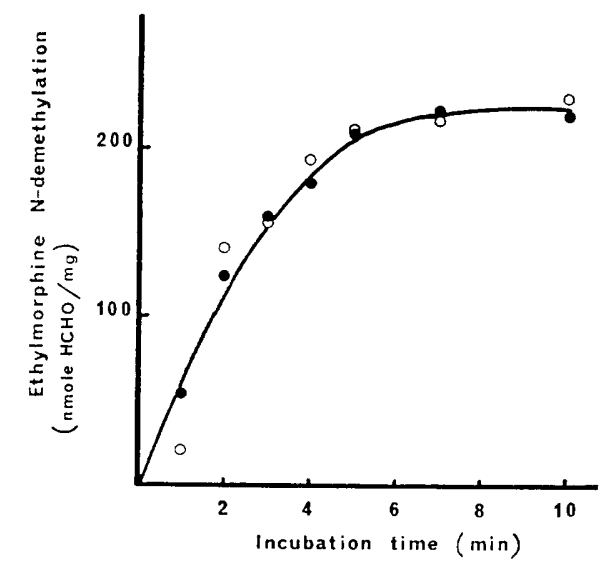

FIG. 3. Effects of spermine on hydrogen peroxide-dependent ethylmorphine Ndemethylation in rat liver microsomes. Microsomal $\mathrm{H}_{2} \mathrm{O}_{2}$-dependent ethylmorphine $\mathrm{N}$-demethylation was measured as described in MATERIALS AND METHODS and the concentration of spermine was $5 \mathrm{mM}$. Each value represents the activity in the presence $(\bigcirc)$ or absence $(0)$ of spermine.

TABLE 3. Effects of polyamines on ethylmorphine N-demethylation by reconstituted system containing cytochrome P-450 isolated from phenobarbital-treated rats

Addition

None
EDTA
Putrescine $(2 \mathrm{mM})$
Spermidine $(1 \mathrm{mM})$
Spermidine $(2 \mathrm{mM})$
Spermine $(1 \mathrm{mM})$
Spermine $(2 \mathrm{mM})$

Ethylmorphine N-demethylation ( $\mu$ mole $\mathrm{HCHO} /$ nmole cytochrome P-450/10 min)

A
0.193
0.182
0.199
0.186
0.188
0.195
0.181

$\mathrm{N}$-Demethylation activities shown in column $\mathrm{A}$ represent the activities in the presence of extracted lipid and those in column B represent the activities in the presence of dilauroyl-L-3-phosphatidylcholine. Each value represents the mean of duplicate determinations. Various concentrations of polyamines as specified in the table, were added to the reaction mixture. 
effects of polyamines on drug oxidations, by a reconstituted monooxygenase system containing cytochrome P-450, isolated from phenobarbital-treated rat liver microsomes, were studied. As can be seen in Table 3, no significant increase in ethylmorphine $\mathrm{N}$-demethylation by the reconstituted system containing either extracted lipid or dilauroyl-L-3-phosphatidylcholine was observed when spermine, spermidine or putrescine was added to the reaction mixture. Lipid peroxidation in the reconstituted system containing extracted lipid was negligible under these experimental conditions $\left(0.013\right.$ to $0.021 \mathrm{OD}_{532}$ per unit of reductase per $10 \mathrm{~min}$ ).

\section{DISCUSSION}

Recently, Chapman (3) has shown that polyamines such as spermine and spermidine stimulated ethylmorphine $\mathrm{N}$-demethylation activity in rat liver. We investigated, herein, the effects of polyamines on ethylmorphine N-demethylation activity, under various incubation periods. As shown in Fig. 1, the linearity of ethylmorphine N-demethylation was prolonged by the addition of spermine and spermidine suggesting that the stimulatory effects of polyamines may be due to stabilization of ethylmorphine $\mathrm{N}$-demethylase. The stimulation of ethylmorphine $\mathrm{N}$-demethylation by spermine was also observed when NADPH was used in place of the NADPH-generating system containing glucose 6-phosphate dehydrogenase (data not shown).

Kamataki and Kitagawa (6) have demonstrated that when EDTA was added to inhibit lipid peroxidation, there was an improvement in the linearity of ethylmorphine $\mathrm{N}$ demethylation in rat liver microsomes. Since we have recently demonstrated the inhibitory effects of spermine and spermidine on rat liver microsomal lipid peroxidation, the effect of spermine on ethylmorphine and aminopyrine $\mathrm{N}$-demethylations and aniline hydroxylation in the presence or absence of lipid peroxidation inhibitor were investigated herein. The stimulatory effects of spermine on ethylmorphine $\mathrm{N}$-demethylation activity were found to be decreased with increase in the concentration of EDTA (Fig. 2). Moreover, $\mathrm{Co}^{2+} \mathrm{Mn}^{2+}$ and 2,2'-bipyridine also decreased in the stimulatory effects of spermine on ethylmorphine $\mathrm{N}$-demethylation activity (Table 2). These results strongly suggested that the stimulatory effect of spermine on ethylmorphine $\mathrm{N}$-demethylation in rat liver microsomes might be due to the inhibitory effect of spermine on lipid peroxidation.

Cumene hydroperoxide, hydrogen peroxide and lipid peroxide such as linoleic acid hydroperoxide have been shown to decompose microsomal cytochrome P-450 and purified cytochrome P-450 $(21,23)$. Therefore, the possibility that spermine exerts a protective effect against cytochrome P-450 destroyed by lipid peroxides was considered. However, spermine had no effect on the linearity of $\mathrm{H}_{2} \mathrm{O}_{2}$ - dependent ethylmorphine $\mathrm{N}$-demethylation. In addition, the findings that the stimulatory effects of polyamines on ethylmorphine $\mathrm{N}$ demethylation were not apparent in the reconstituted monooxygenase system containing either extracted lipid or dilauroyl-L-3-phosphatidylcholine suggest that polyamines do not exert direct stimulatory effects on ethylmorphine $\mathrm{N}$-demethylation (Table 3). Although the amounts of added extracted lipid and dilauroyl-L-3-phosphatidylcholine showed maximum 
activity of ethylmorphine $\mathrm{N}$-demethylation in these experimental conditions, the activity of ethylmorphine $\mathrm{N}$-demethylation in the reconstituted system containing extracted lipid was lower than that in the reconstituted system containing dilauroyl-L-3-phosphatidylcholine. The differences in N-demethylation activities between the two systems may be partly due to the presence of phosphatidylethanolamine in the extracted lipid (24). From these results, it was suggested that the inhibitory effect of spermine on lipid peroxidation might be responsible for the stimulatory effects on drug oxidations. However, in recent years, there is evidence that liver microsomes contain a multiple species of cytochrome P-450 (25-27). Therefore, the possibility that the enhancement of drug oxidation seen with application of spermine and spermidine may be dependent on cytochrome P-450 species employed cannot be ruled out.

Acknowledgement: We thank Miss Y. Naito for skillful technical assistance.

\section{REFERENCES}

1) Strobel, H.W., Lu, A.Y.H., Heidema, J. And Coon, M.J.: Phosphatidylcholine requirement in the enzymatic reduction of hemoprotein P-450 and fatty acid, hydrocarbon, and drug hydroxylation. J. biol. Chem. 245, 4851-4854 (1970)

2) Chaplin, M.D. and Mannering, G.J.: Role of phospholipids in the hepatic microsomal drug-metabolizing system. Mol. Pharmacol. 6, 631-640 (1970)

3) Chapman, S.K.: Polyamines and drug oxidations. Drug Metabo. Dispos. 4, 417-422 (1976)

4) Cohen, S.S.: Introduction to the polyamines, Prentice-Hall, Englewood Cliffs, N.J. (1971)

5) Kitada, M., Igarashi, K., Hirose, S. and Kitagawa, H.: Inhibition by polyamines of lipid peroxide formation in rat liver microsomes. Biochem. biophys. Res. Commun. 87, 388-394 (1979)

6) Kamataki, T. and Kitagawa, H.: Effects of lipid peroxidation on activities of drugmetabolizing enzymes in liver microsomes of rats. Biochem. Pharmacol. 22, 3199-3207 (1973)

7) Kitada, M., Igarashi, T., Kamataki, T. and Kitagawa, H.: Cause of decrease of ethylmorphine $\mathrm{N}$-demethylase activity by lipid peroxidation in microsomes from the rat, guinea pig and rabbit. Japan. J. Pharmacol. 27, 481-489 (1977)

8) Folch, J., Lees, M. And Stanlev, G.H.S.: A simple method for the isolation and purification of total lipids from animal tissues. J. biol. Chem. 226, 497-509 (1956)

9) ImaI, Y. AND SATO, R.: A gel-electrophoretically homogeneous preparation of cytochrome P-450 from liver microsomes of phenobarbital-pretreated rabbits. Biochem. biophys. Res. Commun. 60, 8-14 (1974)

10) Omura, T. and Sato, R.: The carbon monoxide-binding pigment of liver microsomes I. Evidence for its hemoprotein nature. J. biol. Chem. 239, 2370-2378 (1964)

11) Yasukochi, Y. ANd Masters, B.S.S.: Some properties of a detergent-solubilized NADPHcytochrome $c$ (cytochrome P-450) reductase purified by biospecific affinity chromatography. J. biol. Chem. 251, 5337-5344 (1976)

12) Phillips, A.H. and Langdon, R.G.: Hepatic triphosphopyridine nucleotide-cytochrome $c$ reductase: Isolation, characterization, and kinetic studies. J. biol. Chem. 237, 2652$2660(1962)$

13) Kamataki, T., Ozawa, N., Kitada, M., Kitagawa, H. and Sato, R.: The occurrence of an inhibitor of lipid peroxidation in rat liver soluble fraction and its effect on microsomal drug oxidations. Biochem. Pharmacol. 23, 2485-2490 (1974)

14) NASH, T.: The colorimetric estimation of formaldehyde by means of the Hantzsch reaction. Biochem. J. 55, 416-421 (1953)

15) Imai, Y., Ito, A. AND Sato, R.: Evidence for biochemically different types of vesicles in the hepatic microsomal fraction. J. Biochem. 60, 417-428 (1966) 
16) Lowry, O.H., Rosebrough, N.J., Farr, A.L. and Randall, R.J.: Protein measurement with the Folin phenol reagent. J. biol. Chem. 193, 265-275 (1951)

17) Gram, T.E. and Fouts, J.R.: Effect of $\alpha$-tocopherol upon lipid peroxidation and drug metabolism in hepatic microsomes. Arch. Biochem. Biophys. 114, 331-335 (1966)

18) Kitada, M., Kamataki, T. and Kitagawa, H.: Effects of lipid peroxidation on the microsomal electron transport system and the rate of drug metabolism in rat liver. Chem. Pharm. Bull. (Tokyo) 22, 752-756 (1974)

19) Hrycay, E.G., Gustaffsson, J.-Å., Ingelman-Soundberg, M. and Ernster, L.: The involvement of cytochrome P-450 in hepatic microsomal steroid hydroxylation reactions supported by sodium periodate, sodium chlorite, and organic hydroperoxides. Europ. J. Biochem. 61, 43-52 (1976)

20) Rahimtula, A.D. ANd O'Brien, P.J.: Hydroperoxide dependent O-dealkylation reactions catalyzed by liver microsomal cytochrome P-450. Biochem. biophys. Res. Commun. 62, 268-275 (1975)

21) Nordblom, G.D., White, R.E. And CoOn, M.J.: Studies on hydroperoxide-dependent substrate hydroxylation by purified liver microsomal cytochrome P-450. Archs. Biochem. Biophys. 175, 524-533 (1976)

22) Akhrem, A.A., Boкut, A.B. and Metelitza, D.I.: Kinetics of cumene hydroperoxidedependent aniline hydroxylation involving cytochrome P-450 in microsomal and solubilized forms. Biochem. biophys. Res. Commun. 77, $20-27$ (1977)

23) Jeffery, E., Kotake, A.A., Azhary, R. el and Mannering, G.J.: Effects of linoleic acid hydroperoxide on the hepatic monooxygenase systems of microsomes from untreated, phenobarbital-treated and 3-methylcholanthrene-treated rats. Mol. Pharmacol. 13, 415-425 (1977)

24) Coon, M.J., Autor, A.P. And Strobel, H.W.: Role of phospholipid in electron transfer in a reconstituted liver microsomal enzyme system containing cytochrome P-450. Chem. Biol. Interactions, 3, 248-250 (1971)

25) Welton, A.F. ANd Aust, S.D.: Multiplicity of cytochrome P-450 hemoproteins in rat liver microsomes. Biochem. biophys. Res. Commun. 56, 898-906 (1974)

26) Thomas, P.E., Lu, A.Y.H., Ryan, D., West, S.B., Kawalek, J. and Levin, W.: Multiple forms of rat liver cytochrome P-450. Immunochemical evidence with antibody against cytochrome P-448. J. biol. Chem. 251, 1385-1391 (1976)

27) Thomas, P.E., Lu, A.Y.H., Ryan, D., West, S.B., Kawalek, J. and Levin, W.: Immunochemical evidence for six forms of rat liver cytochrome P-450 obtained using antibodies against purified rat liver cytochrome P-450 and P-448. Mol. Pharmacol. 12, 746-758 (1976) 